\title{
Fatigue Behavior of Dissimilar Friction Stir Welds between Cast and Wrought Aluminum Alloys
}

\author{
Y. Uematsu, ${ }^{1, a}$ Y. Tozaki, ${ }^{2}$ K. Tokaji, ${ }^{1, b}$ and M. Nakamura ${ }^{1}$ \\ ${ }^{1}$ Gifu University, Gifu, Japan \\ ${ }^{2}$ Gifu Prefectural Research Institute for Machinery and Materials, Seki, Japan \\ a yuematsu@gifu-u.ac.jp, ${ }^{\text {b }}$ tokaji@gifu-u.ac.jp
}

Cast aluminum alloy, AC4CH-T6, and wrought aluminum alloy, A6061-T6, were joined by means of friction stir welding (FSW) technique. The effect of microstructure and post heat treatment on fatigue behavior of the dissimilar joints was investigated. Near the weld centre, Vickers hardness was lower than in the parent metals and the hardness minima were observed along the trace route of FSW tool's shoulder edge. Tensile fracture took place on A6061 side where the hardness was minimal, resulting in the lower static strength of the dissimilar joints than $A C 4 C H$ or $A 6061$. Fatigue fracture occurred on $\mathrm{ACACH}$ side due to casting defects and the fatigue strength of the dissimilar joints was similar to that of $A C 4 C H$, but lower than that of A6061. Friction stir process (FSP) and post heat treatment successfully improved the fatigue strength of the dissimilar joints up to that of the parent metal, A6061.

Keywords: fatigue, friction stir welding, dissimilar joint, aluminum alloy.

Introduction. Aluminum alloys are increasingly used for transportation systems, particularly in automobiles, with the aim of weight saving. Wrought and cast aluminum alloys are applied to body skin and complex shape components, respectively, and joining between both alloys is often required. Friction stir welding (FSW) is a recently developed solid state welding process and now being used for joining aluminum alloys for which fusion welding is difficult $[1,2]$. Furthermore, it is known that FSW technique is suitable for joining dissimilar metals because of solid state process [3]. In order to apply dissimilar joints to load-bearing components, it is significant to understand their fatigue behavior. In the present study, the fatigue behavior of the dissimilar FSW joints between cast aluminum alloy, AC4CH-T6 and wrought aluminum alloy, A6061-T6, was investigated. The effect of microstructure and post heat treatment on fatigue behavior is discussed.

Experimental Details. Materials. The materials used are cast aluminum alloy, AC4CH-T6, and wrought aluminum alloy, A6061-T6. Their chemical compositions (wt.\%) and mechanical properties are listed in Tables 1 and 2, respectively. The microstructures of the parent metals are shown in Fig. 1. A typical dendrite structure of cast aluminum alloy is recognized in $\mathrm{AC} 4 \mathrm{CH}$ (Fig. 1a), while elongated grains due to rolling process are seen in A6061 (Fig. 1b), where the average grain size measured along the rolling direction was about $90 \mu \mathrm{m}$.

Welding Condition and Specimen. Plates with a thickness of $5 \mathrm{~mm}$ were cut from casting blocks of $\mathrm{AC} 4 \mathrm{CH}$ by wire cut electric spark machining. $\mathrm{AC} 4 \mathrm{CH}$ plates were butt welded with A6061 plates of the same thickness by FSW technique to form the stock from which fatigue specimens were machined. The upper and lower skins of the stock were removed by $0.5 \mathrm{~mm}$ depth by milling process. The configuration of fatigue specimens is shown in Fig. 2. The centre of the gauge section corresponds to the welding line and the loading direction is perpendicular to the welding direction. The friction stir tool was composed of a pin and a shoulder whose diameter is 6 and $14 \mathrm{~mm}$, respectively. The tool-to-workpiece angle was $3^{\circ}$ from the vertical axis. The plates were joined with the tool travel speed of $150 \mathrm{~mm} / \mathrm{min}$ and the tool rotational speed of $1000 \mathrm{rpm}$. A6061 was arranged on the advancing side (AS) where the tool travel direction coincides with the

(C) Y. UEMATSU, Y. TOZAKI, K. TOKAJI, M. NAKAMURA, 2008 
Fatigue Behavior of Dissimilar Friction Stir Welds...

$\mathrm{T}$ a $\mathrm{b} l \mathrm{e} 1$

Chemical Compositions of Materials

\begin{tabular}{|c|c|c|c|c|c|c|c|c|c|c|}
\hline Material & $\mathrm{Si}$ & $\mathrm{Mg}$ & $\mathrm{Zn}$ & $\mathrm{Fe}$ & $\mathrm{Ni}$ & $\mathrm{Ti}$ & $\mathrm{Sr}$ & $\mathrm{Cu}$ & $\mathrm{Mn}$ & $\mathrm{Cr}$ \\
\hline AC4CH-T6 & 7.10 & 0.36 & 0.01 & 0.12 & 0.022 & 0.11 & 0.005 & - & - & - \\
A6061-T6 & 0.58 & 0.96 & 0.02 & 0.41 & - & 0.04 & - & 0.28 & 0.03 & 0.23 \\
\hline
\end{tabular}

T a b 1 e 2

Mechanical Properties of Materials

\begin{tabular}{|c|c|c|c|c|}
\hline Material & $\begin{array}{c}0.2 \% \text { proof stress } \\
\sigma_{02}, \mathrm{MPa}\end{array}$ & $\begin{array}{c}\text { Tensile strength } \\
\sigma_{b}, \mathrm{MPa}\end{array}$ & $\begin{array}{c}\text { Elongation } \\
\delta, \%\end{array}$ & $\begin{array}{c}\text { Elastic modulus } \\
E, \mathrm{GPa}\end{array}$ \\
\hline AC4CH-T6 & 165 & 230 & 5.2 & 72.5 \\
A6061-T6 & 275 & 310 & 12.0 & 68.3 \\
\hline
\end{tabular}

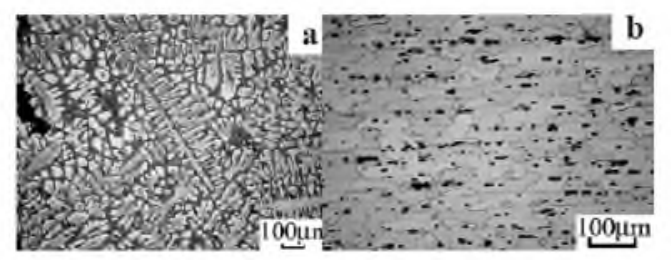

Fig. 1. Microstructures of parent metals: (a) $\mathrm{AC4CH}$, (b) $\mathrm{A} 6061$.

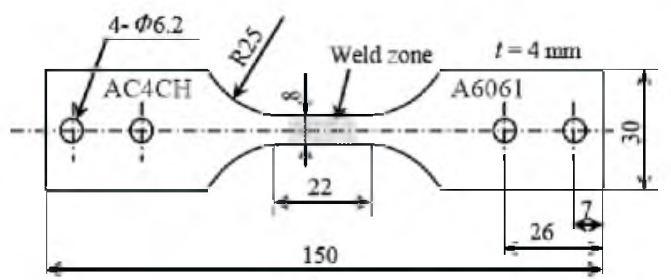

Fig. 2. Configuration of fatigue specimen.

tool rotational direction. Dissimilar joints, in which A6061 was arranged on the retreating side (RS), were also examined, but there existed no notable differences in microstructure, hardness profile and tensile strength.

The fatigue fracture of the as-welded joints took place on $\mathrm{AC} 4 \mathrm{CH}$ side due to casting defects. Therefore, friction stir process (FSP) was applied to as-welded joints in order to eliminate casting defects in the gauge section. The friction stir tool was inserted in $\mathrm{AC} 4 \mathrm{CH}$ at the locations of 6 and $12 \mathrm{~mm}$ away from the weld centre. The tool geometry, tool travel and rotational speeds in FSP were the same as those in FSW. Furthermore, post T6-heat treatment was applied to FSPed joints. Hereafter, the specimens are referred to as as-welded (FSPed) and post heat treated (PHTed) joints.

Procedures. Axial fatigue tests were conduced on an electro-hydraulic fatigue testing machine at a frequency of $10 \mathrm{~Hz}$ and a stress ratio $R=-1$ (fully reversed loading) in laboratory air.

Results and Discussion. Microstructure. Figure 3 shows a macroscopic view of the longitudinal section near the weld zone in an as-welded joint. It can be seen that both materials are sufficiently stirred in the weld zone, where $\mathrm{AC4CH}$ on the RS moves to the AS near the upper surface, while A6061 on the AS moves to the RS near the lower surface. The magnified views of the regions $A \sim D$ in Fig. 3 are revealed in Fig. 4. In $\mathrm{AC} 4 \mathrm{CH}$ near the weld centre (Fig. 4a), dendrite structure completely disappears and eutectic silicon distributes uniformly. In A6061 near the weld centre (Fig. 4c), equiaxed 
fine grains, whose average size is about $8 \mu \mathrm{m}$, are seen. It is believed that the grain refinement of A6061 is due to dynamic recrystallization during welding process [1] Figure $4 \mathrm{~b}$ shows the region $B$ which is the boundary between $\mathrm{AC} 4 \mathrm{CH}$ and $\mathrm{A} 6061$. The boundary line between both materials is distinctly visible, indicating that FSW is a solid state process. In the region $D$ (Fig. 4d), both materials are arranged in alternative layers due to stirring under solid state.

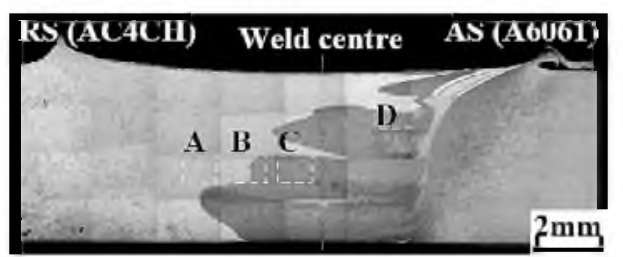

Fig. 3. Macroscopic appearance in cross section of as-welded joint.
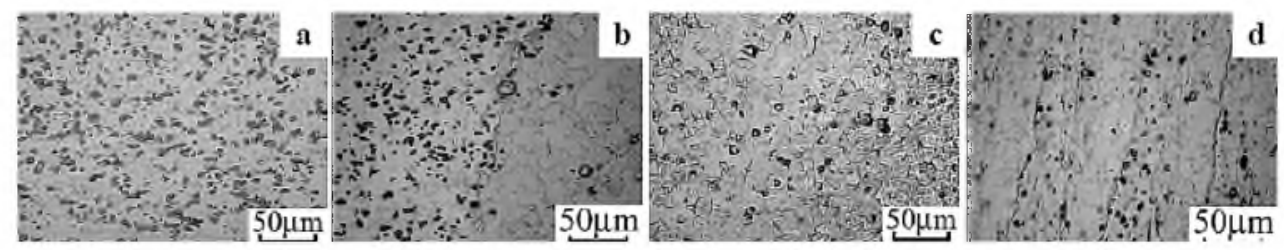

Fig. 4. Microstructures of as-welded joint: (a), (b), (c) magnified views of region $A, B, C$, and (d) region $D$ in Fig. 3, respectively.

Macroscopic appearance in the cross section of an FSPed joint is shown in Fig. 5, in which the dotted lines represent the locations of the centre of friction stir tool during FSP Both materials are stirred more severely in the vicinity of the weld centre of the FSPed joint. The microstructure of FSPed AC4CH area is similar to that of the region $A$ in Fig. 3 (Fig. 4a). In the PHTed joint, it was found that remarkable grain growth took place near the weld centre in A6061 [1], whereas there was no or little influence on the microstructure in $\mathrm{AC} 4 \mathrm{CH}$.

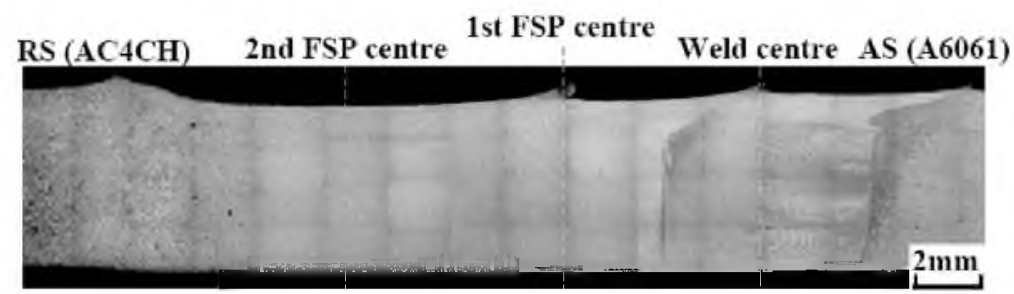

Fig. 5. Macroscopic appearance in cross section of FSPed joint.

Hardness Profile. The Vickers hardness profiles are shown in Fig. 6. The as-welded joint experiences softening inside the weld zone, which may be attributed to the dissolution of precipitates due to temperature rise during FSW process. The hardness minima are located on the both sides about $7 \mathrm{~mm}$ away from the weld centre, as shown by arrow $A$ in Fig. 6. The distance between the hardness minima coincides with the diameter of FSW tool's shoulder, indicating that remarkable softening took place along the trace route of FSW tool's shoulder edge. Such hardness minima are also recognized in A6061-T6 FSW joints [1]. The softening area expands to $\mathrm{AC4CH}$ side in the FSPed joint. The hardness minima are observed as shown by arrow $B$ in the figure, which correspond to the locations of tool's shoulder edge during FSW and FSP. The PHTed joint exhibits nearly the same hardness value as the parent metals. 


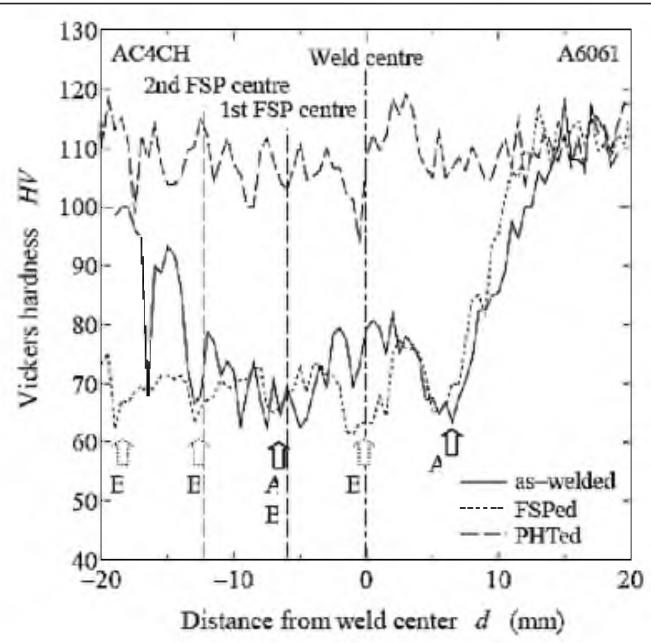

Fig. 6. Hardness profiles.

Tensile Strength. The average tensile strength, $\sigma_{b}$, of three as-welded joints was $198 \mathrm{MPa}$, which was lower than those of the parent metals. It was found that all joints fractured on A6061 side where the hardness was minimal.

Fatigue Strength. Figure 7 represents the $S-N$ diagram. The fatigue strength of the as-welded joint is similar to that of the parent metal, $\mathrm{AC} 4 \mathrm{CH}$. It should be noted that the fatigue fracture took place on $\mathrm{AC} 4 \mathrm{CH}$ side and the location of fracture was different from tensile fracture. SEM micrograph of fracture surface near crack initiation site of an as-welded joint is revealed in Fig. 8a. Casting defect is recognized at the crack initiation site, thus resulting in the similar fatigue strength to the parent metal, $\mathrm{AC} 4 \mathrm{CH}$. On the other hand, the FSPed joint shows nearly the same fatigue strength as the parent metal, $\mathrm{AC} 4 \mathrm{CH}$, in high stress region, but considerably higher fatigue limit. Figure $8 \mathrm{~b}$ represents SEM micrograph of fracture surface near crack initiation site of an FSPed joint, where casting defect is not seen. This indicates that casting defects were eliminated by FSP, which led to the improvement of fatigue limit. Fatigue fracture of the FSPed joints took place at the locations of the hardness minima, arrow $B$ in Fig. 6. It is believed, therefore, the fatigue strength in high stress region was not improved due to the softening in the weld zone. The fatigue strength of the PHTed joint is nearly the same as that of the parent metal, A6061, due to the recovery of hardness by post heat treatment. However, fatigue fracture still occurred along the trace route of FSW tool's shoulder edges shown by arrow $B$ in Fig. 6 .

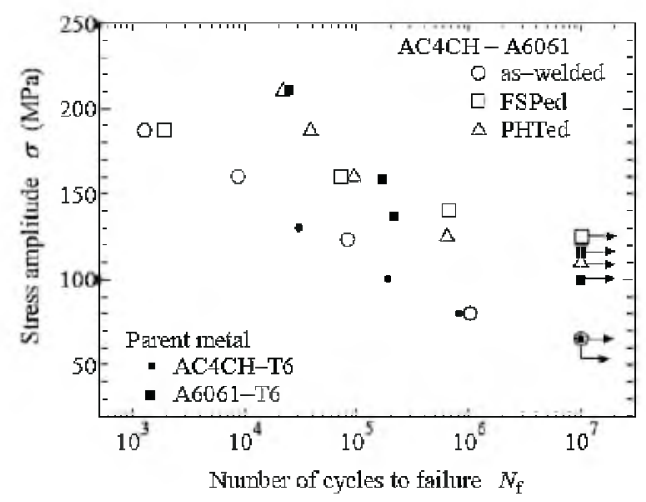

Fig. 7. $S-N$ diagram. 

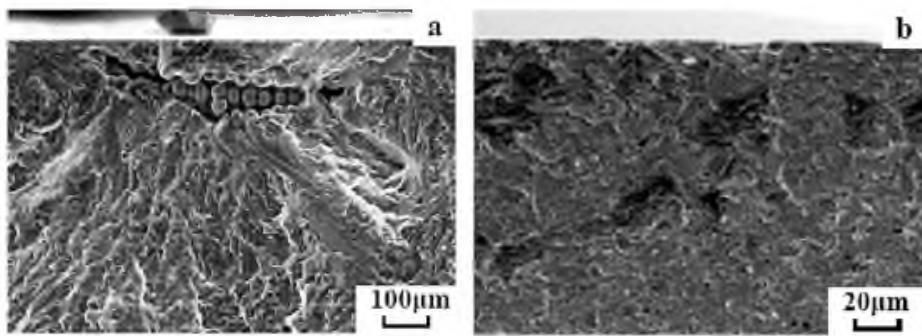

Fig. 8. SEM micrographs showing crack initiation site: (a) as-welded ( $\sigma=160 \mathrm{MPa}$ ), (b) FSPed $(\sigma=160 \mathrm{MPa})$

Conclusions. Fully reversed axial fatigue tests were conducted using friction stir welded dissimilar joints between cast aluminum alloy, AC4CH-T6, and wrought aluminum alloy, A6061-T6. The dissimilar joints showed nearly the same fatigue strength as the parent metal, $\mathrm{AC} 4 \mathrm{CH}$, because cracks were initiated from casting defects. By the application of both friction stir process and post heat treatment, the fatigue strength of dissimilar joints was successfully improved up to that of the parent metal, A6061.

1. Y. Uematsu, K. Tokaji, Y. Tozaki, and H. Shibata, Proc. of the 16th European Conference of Fracture (ECF 16) (2006).

2. M. A. Sutton, B. Yang, A. P. Reynolds, and T. Taylor, Mater. Sci. Eng., A323, 160 (2002).

3. A. Steuwer, M. J. Peel, and P. J. Withers, Mater. Sci. Eng., A441, 187 (2006).

Received 28. 06. 2007 